\title{
Elevated Synthesis of an Axonally Transported Protein Correlates with Axon Outgrowth in Normal and Injured Pyramidal Tracts
}

\author{
Katherine Kalil ${ }^{*}$ and J. H. Pate Skene $\nmid$ \\ *Department of Anatomy and Neurosciences Training Program, University of Wisconsin, Madison, Wisconsin \\ 53706, and fDepartment of Neurobiology, Stanford University, Stanford, California 94305
}

\begin{abstract}
Axons of the adult mammalian CNS typically fail to regenerate after injury. Among the hypotheses to account for this failure is the proposition that certain axonal proteins necessary for axon growth are expressed in much greater abundance in developing than in mature neurons, and that these proteins are not reinduced after injury to mature axons (Skene and Willard, 1981b). In the present experiments, we have found that hamster pyramidal tract neurons synthesize an acidic, $43 \mathrm{~K}$ protein that is transported into growing axons during the first 2 weeks of postnatal development, and then declines at least an order of magnitude by the fourth postnatal week. The decline in synthesis of the $43 \mathrm{~K}$ protein coincides with the cessation of pyramidal tract axon elongation. This protein resembles a "growth-associated protein," GAP-43, which is induced during regeneration of CNS axons in lower vertebrates. 'The $43 \mathrm{~K}$ protein in hamster pyramidal tract neurons is not reinduced after axotomy in adult animals, which correlates with the failure of the injured axons to regenerate. Injury to neonatal pyramidal tract axons does not reverse or delay the decline in $43 \mathrm{~K}$ protein synthesis. This is consistent with previous findings (Kalil and Reh, 1982) that pyramidal tract axons regrow for only a brief period after neonatal injury. Taken together, these results lend support to the hypothesis that synthesis of GAP-43 is important for axon growth in development and regeneration.
\end{abstract}

Severed axons typically do not regenerate in the CNS of adult mammals. In contrast, axons in the PNS regenerate vigorously, as do many CNS axons in amphibians and fishes. Regeneration in several such instances has been shown to be accompanied by specific 20 - to 100 -fold increases in the synthesis of a small number of proteins that are subsequently transported rapidly into the growing axons (Benowitz and Lewis, 1983; Benowitz et al., 1981; Heacock and Agranoff, 1982; Skene and Willard, $1981 \mathrm{a}, \mathrm{b})$. We have proposed that elevated synthesis of these "growth-associated proteins" (GAPs) is imporlant for axon growth (Skene and Willard, 1981a, b). Thus, during normal development, one would also expect to find elevated synthesis of these proteins. At least one of the GAPs (GAP-43) does appear to be developmentally expressed by many neurons in the mammalian CNS (Jacobson et al., 1986; Skene and Willard, $1981 \mathrm{~b})$, but it has not been possible to show a precise temporal correlation between GAP-43 synthesis and axon outgrowth. If elevated GAP synthesis were directly involved in axon growth

\footnotetext{
Received Nov. 25, 1985; revised Mar. 11, 1986. accepted Mar. 17, 1986.

Pilot experiments for this work were carried out in the laboratory of Dr. J. A Freeman, whom we thank for support and advice. We also thank Ildiko Virag and Cheryl Adams for excellent technical assistance. This work was supported by NIH Grant NS20178 and the Isabela Niemela Fund (J.H.P.S.) and by NSF Grant BNS-8311517 and NIH Grant NS14428, which has becn designatcd a Javits Neuroscience Investigator Award (K.K.). J.H.P.S. is a recipient of an Alfred P. Sloan Fellowship and a Searle Scholars Award.

Copyright (C) 1986 Society for Neuroscience 0270-6474/86/092563-08\$02.00/0
}

in the mammalian CNS, then failure to reinduce these proteins after injury might limit the axon's ability to carry out some step(s) in axon regeneration (Skene and Willard, 1981b). It is therefore important to determine whether failure of axotomy to reinduce GAP synthesis is a general feature of mammalian CNS neurons.

The hamster pyramidal tract provides an ideal system for studying the relationship between axon outgrowth and expression of GAPs. This pathway arises from neurons in layer $\mathrm{V}$ of the sensorimotor cortex, and the axons extend to all levels of the spinal cord. These axons form a discrete pathway that is accessible on the ventral surface of the medulla (Fig. 1). In hamsters, pyramidal tract axons grow out almost entirely postnatally, and the precise timing of axon elongation into the spinal cord over the first 2 postnatal weeks has been established (Reh and Kalil, 1981). Moreover, if axons are severed during this growth period, they are able to regrow and establish functional connections (Kalil and Reh, 1979, 1982; Reh and Kalil, 1982). After similar lesions in adult hamsters, the pyramidal tract axons fail to regenerate. We have now examined proteins synthesized and axonally transported in hamster pyramidal tract neurons during developmental axon clongation and after injury to neonatal and adult axons.

\section{Materials and Methods}

\section{Labeling of axonally transported proteins}

Syrian golden hamsters (Mesocricetus auratus) ranging in age from $4 \mathrm{~d}$ to adult were anesthetized by injection of saline-diluted Nembutal. ${ }^{3.5} \mathrm{~S}-$ methionine $(150-450 \mu \mathrm{Ci})$ was pressure injected into $2-3$ sites in the sensorimotor cortex by means of glass micropipettes $(40-50 \mu \mathrm{m}$ tip diameters). A total volume of approximately $0.5 \mu \mathrm{l}$ was injected over a period of 45-60 min. We allowed 3-5 hr for labeled proteins to be transported along axons, and then the animals were anesthetized and the brains rapidly removed. A small region of the ventral medulla encompassing the pyramidal tract was dissected rapidly and frozen on dry ice.

In some experiments, samples of sensorimotor cortex surrounding the injection sites were dissected out and frozen.

To label proteins transported in regenerating toad optic nerves axons, we anesthetized toads (Bufo marinus) on ice and crushed the left optic nerves near the optic chiasm. We reanesthetized the toads and injected ${ }^{35} \mathrm{~S}$-methionine into the posterior chamber of the eye 3 weeks later. The optic nerves were removed and frozen $6 \mathrm{hr}$ after labeling.

\section{Pyramidal tract lesions}

Animals up to $8 \mathrm{~d}$ of age were anesthetized by cooling on ice; older animals were anesthetized with Nembutal. The medullary pyramids were exposed by a ventral approach through an opening in the basioccipital bone. With the basilar artery as a landmark for the midline, the left pyramidal tract was cut $2-3 \mathrm{~mm}$ rostral to the pyramidal decussation, using a fine scalpel blade. Infant animals were returned to the mother's nest. Animals were allowed to survive 3-15 d after surgery, and axonally transported proteins were labeled as described above. Seg- 

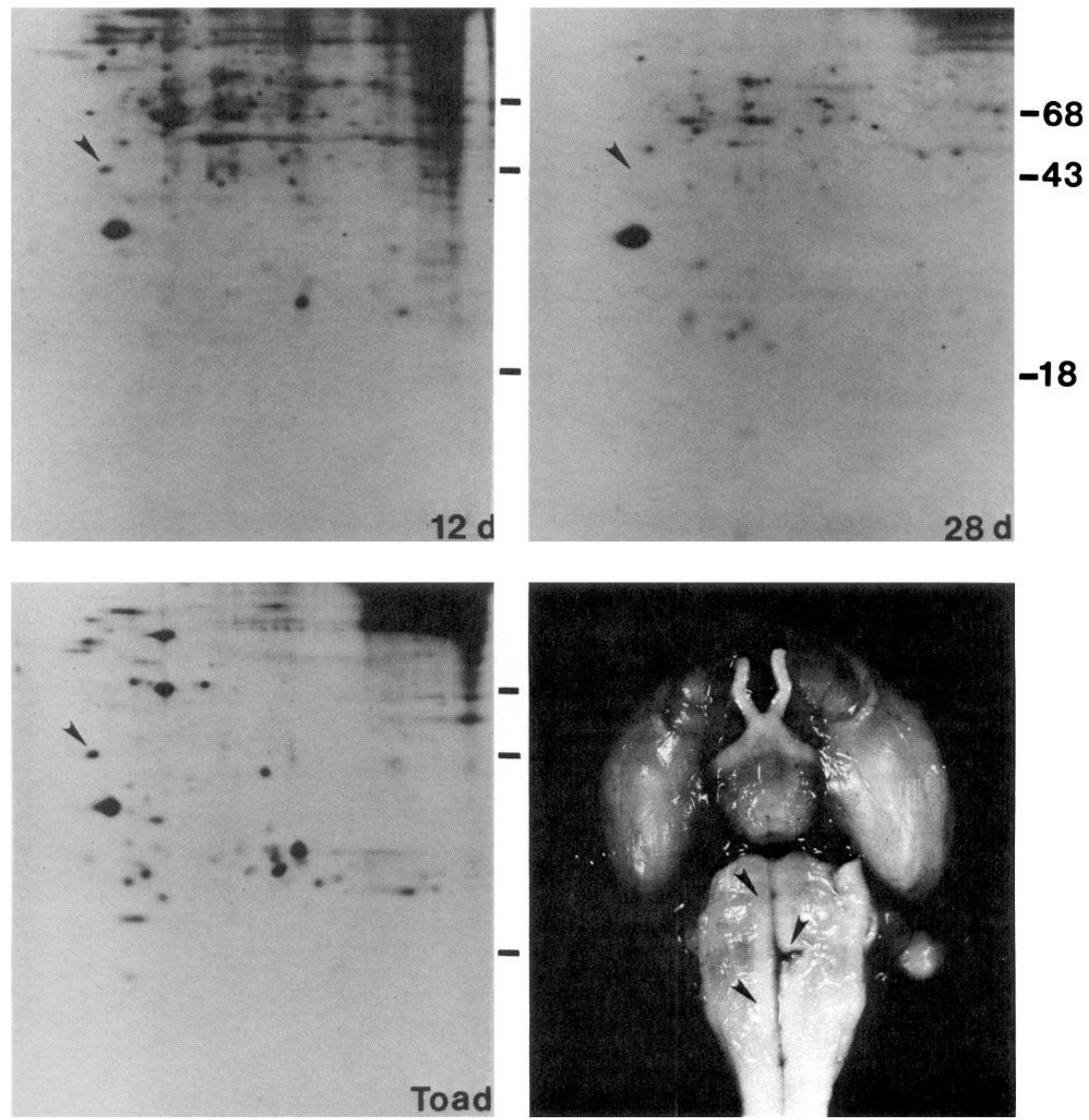

Figure 1. Developmental expression in hamster pyramidal tract of a protein similar to GAP-43 from regenerating toad optic nerves. Axonal proteins synthesized in developing (12 d) and mature ( $28 \mathrm{~d})$ pyramidal tract neurons were compared with proteins transported into regenerating axons in toad optic nerves. Arrows indicate a developmentally regulated protein in hamsters that comigrates with GAP-43. Similar amounts of total radioactivity were applied to each gel. Numbers at right indicate the positions of molecular-weight markers: BSA $(68,000)$, ovalbumin $(43,000)$, and $\beta$-lactoglobulin $(18,000)$. All fluorographs are oriented with the acidic side to the left. Lower right, Photograph shows a ventral view of an adult hamster brain, illustrating the segment of pyramidal tract used in these analyses (between arrows at left). The arrow at right shows the position of a typical pyramidal tract lesion.

ments of the pyramidal tract rostral to the lesion site were removed for analysis.

\section{Analysis of labeled proteins}

Frozen tissues containing labeled proteins were homogenized in $\mathrm{H}$ buffer (10 mM Tris- $\mathrm{HCl}, \mathrm{pH} 7.5 ; 2 \mathrm{~mm}$ EDTA; $5 \mathrm{~mm}$ dithiothreitol). The homogenates were centrifuged at $100,000 \times \mathrm{g}$ for $30 \mathrm{~min}$, and the pellets were dissolved in S1 buffer (1\% SDS, $5 \mathrm{~mm}$ dithiothreitol) and heated $3 \mathrm{~min}$ at $90-100^{\circ} \mathrm{C}$. After cooling to room temperature, the dissolved samples were diluted $1: 1$ with S2 buffer (10\% nonidet P-40; $8 \mathrm{M}$ urea;
$5 \mathrm{~mm}$ dithiothreitol). Aliquots were removed for scintillation counting to determine total particulate-fraction radioactivity.

Two-dimensional gel electrophoresis was carried out essentially according to O'Farrell (1975), using conditions described previously (Skene and Willard, 1981a). Isoelectric focusing in the first dimension employed commercial Ampholytes in the pH ranges of 3.5-10 and 5-7, mixed in a ratio of 2:1. Second-dimension electrophoresis was in the buffer system of Laemmli (1970), with either $12 \%$ polyacrylamide or linear gradients of $5-15 \%$ polyacrylamide and a constant ratio of acrylamide to bisacrylamide of 33:1. SDS was electrophoresis grade from Bio-Rad. In some cases, the second-dimension gels contained $8 \mathrm{~m}$ urea at $\mathrm{pH} 9.2$, 

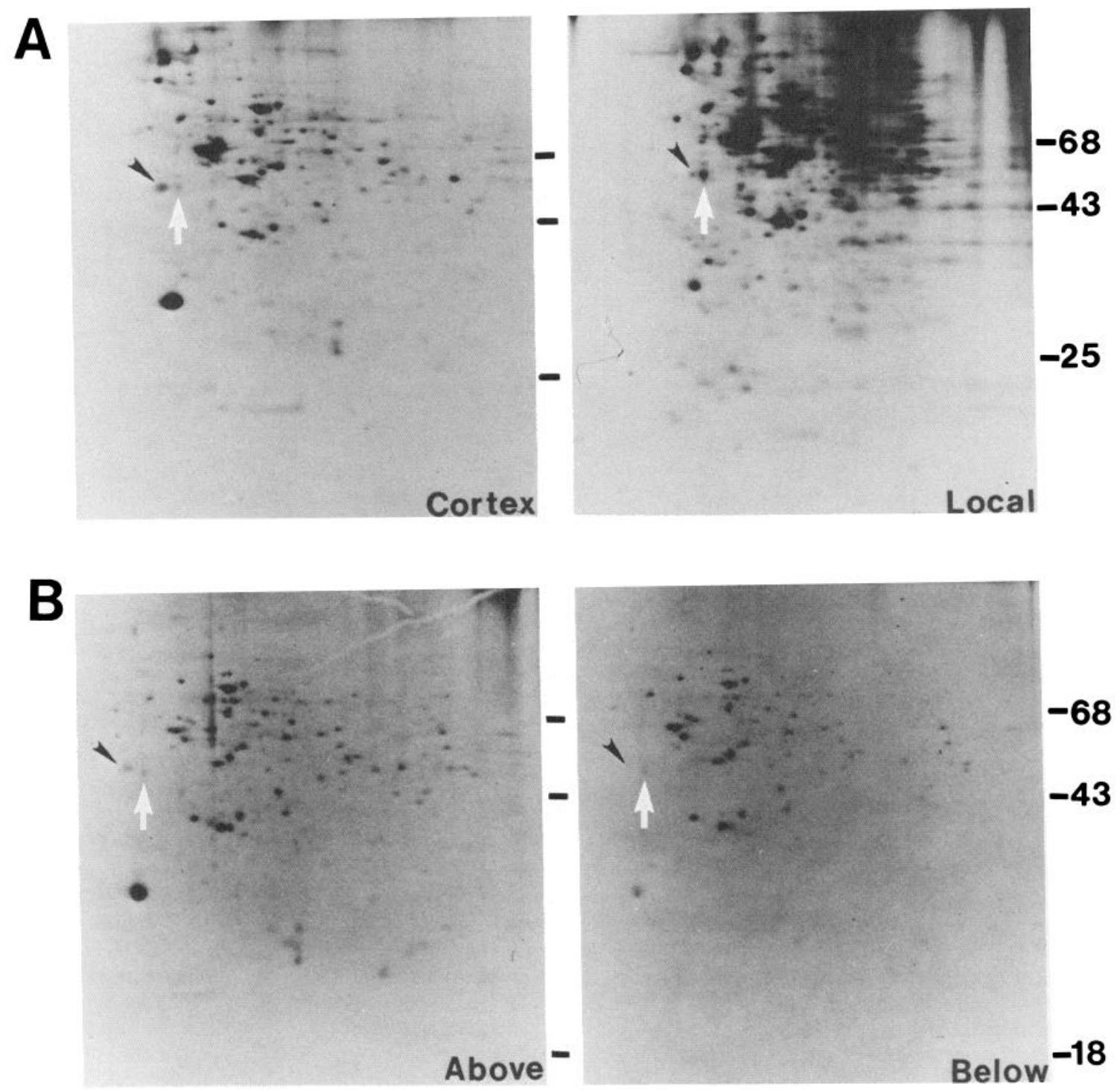

Figure 2. Axonal transport of GAP-43. A, Pyramidal tract proteins were labeled in 12-d-old hamsters either by injection of ${ }^{35}$ S-methionine into sensorimotor cortex (Cortex) or by local application of the label to the vicinity of the medullary pyramidal tract (Local). Labeled proteins in the pyramidal tract were recovered $2 \frac{1}{2} \mathrm{hr}$ after labeling. GAP-43 labeling is much heavier after cortical injection than after local labeling, implying that GAP-43 is transported in pyramidal tract axons originating in the cortex. The 2 fluorographs shown do not represent equal cpm-d of exposure. Gel at right was overexposed to show the trace labeling of GAP-43. B. Pyramidal tract was cut in an 8-d-old hamster and ${ }^{35}$ S-methionine injected into the sensorimotor cortex $4 \mathrm{~d}$ later. Three hours after labeling, the segment of the pyramidal tract just above the lesion and the segment just below the lesion were removed and the labeled proteins analyzed. Results show that labeled GAP-43 is among the proteins that do not pass beyond the lesion site. GAP-43 (dark arrowheads) should not be confused with a locally labeled protein (white arrows) that migrates close to GAP-43 on these gels.

and SDS was replaced with a mixture of tetradecyl and dodecyl sulfates (Sequanal grade SDS, Pierce Biochemicals).

Gels were prepared for fluorography using the APEX system (Jen and Thach, 1982) and exposed to preflashed X-ray film at $-80^{\circ} \mathrm{C}$ (Laskey and Mills, 1975). The lengths of exposures were calculated so that the product of total radioactive counts loaded on a gel times the length of exposure (in cpm-d) were equal for samples to be compared.

\section{Results}

\section{A developmentally regulated protein in pyramidal} tracts is similar to toad GAP-43

To examine developmental regulation of proteins in hamster pyramidal tract neurons, we labeled proteins synthesized by these neurons in normal hamsters of various ages (4-32 d) and analyzed proteins rapidly transported into axons of the medullary pyramidal tract. Figure 1 shows that a very acidic protein with an apparent molecular weight of 43,000 and an apparent isoelectric point of 4.5 is synthesized and transported at a much higher level in 12-d-old hamsters than in 4-week-old animals. Densitometric scanning shows that labeling of this protein, relative to total radioactivity on each gel, declines 10-12-fold between 12 and $28 \mathrm{~d}$ of age. This $43 \mathrm{~K}$ protein is the only rapidly axonally transported protein that we can reproducibly show to be more heavily labeled in neonatal than mature animals. Other spots that in Figure 1 appear to be more heavily labeled in the 12-d-old animal either are not axonally transported (see below) or cannot be observed consistently. In particular, one polypep- 


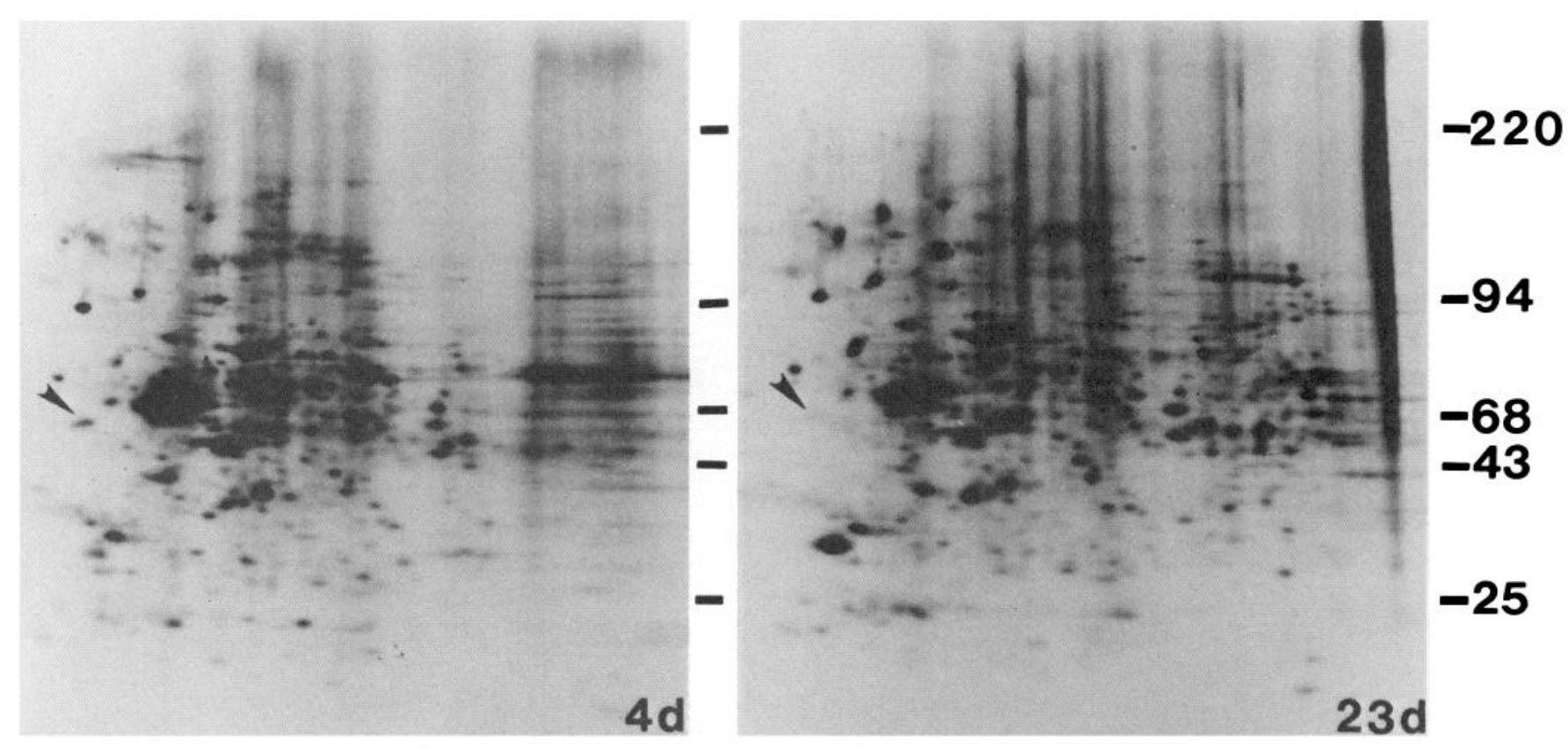

Figure 3. Developmental regulation of GAP-43 in sensorimotor cortex. The region of sensorimotor cortex, including the cell bodies of pyramidal tract neurons, was removed and analyzed $3 \mathrm{hr}$ after injecting ${ }^{35} \mathrm{~S}$-methionine into immature $(4 \mathrm{~d})$ and older $(23 \mathrm{~d})$ animals. For the samples shown, the SDS electrophoresis in the second dimension was carried out on gels containing linear gradients of 5-15\% acrylamide, in the absence of urea. The same total amount of radioactivity was applied to each gel. The position corresponding to GAP- 43 from pyramidal tract samples is indicated by arrows.

tide with an apparent molecular weight of approximately 24,000 Da appears in the $12 \mathrm{~d}$ sample, but not the $28 \mathrm{~d}$ sample, shown in Figure 1. Because this polypeptide does not appear consistently in other samples from these ages, we cannot assess whether it is axonally transported or developmentally regulated.

The developmentally regulated $43 \mathrm{~K}$ protein from hamster pyramidal tract comigrates on these 2-dimensional gels with GAP-43, a protein induced and rapidly transported into axons during regeneration of toad optic nerves (Skene and Willard, 1981a). Another similarity between toad GAP-43 and the developmentally regulated hamster protein is their aberrant behavior in SDS gel electrophoresis. In the absence of urea, the apparent molecular weights of both proteins increase with decreasing acrylamide concentrations (Jacobson et al., 1986). On our standard $12 \%$ polyacrylamide gels, both the hamster protein and GAP-43 from toads show somewhat higher apparent molecular weights in the absence of urea (approximately $46 \mathrm{~K}$ in Figs. $2,4,5)$ than in the presence of $8 \mathrm{M}$ urea (43K in Fig. 1; and Skene and Willard, 1981a, b). Although we do not know the structural basis of this behavior, it is sufficiently unusual to serve as an additional empirical basis for comparison of the toad and hamster proteins. Finally, an antiserum raised against a developmentally regulated protein from rat brain recognizes both toad GAP-43 and the hamster protein described here (Jacobson et al., 1986). Given these similarities, we will refer to the hamster protein as GAP-43.

\section{Axonal transport of hamster GAP-43}

It is important to confirm that the observed changes in the labeling of GAP-43 reflect its synthesis in pyramidal tract neurons and transport into their axons. It is possible that labeling of GAP-43 in the pyramidal tract represents local incorporation of free ${ }^{35} \mathrm{~S}$-methionine, rather than axonal transport of GAP-43 from the cortex. To control for this possibility, we applied ${ }^{35} \mathrm{~S}$ methionine directly to the pyramidal tract and compared the proteins labeled in this way with the labeled proteins appearing in the tract after injecting the label into the cortex. It is apparent from Figure $2 A$ that many of the proteins labeled in the pyramidal tract after cortical injection can be accounted for by local incorporation of free label but that GAP-43 is among the proteins that are much more heavily labeled after cortical injection, implying that they are transported in pyramidal tract axons. Additional evidence for axonal transport of GAP-43 is that the labeled protein fails to pass beyond a lesion that interrupts pyramidal tract axons. To show this, we injected ${ }^{35} \mathrm{~S}$-methionine into the sensorimotor cortex of neonatal animals in which the pyramidal tract had been cut. Labeled GAP-43 appeared in the segments of pyramidal tract just above the lesions, but did not appear below the lesions, indicating that the lesions had interrupted axonal transport of the protein (Fig. $2 B$ ).

We considered the possibility that axonal transport, rather than synthesis, of GAP-43 changes during development. Direct analysis of labeled proteins from sensorimotor cortex, containing the cell bodies of pyramidal tract neurons, shows that GAP43 is synthesized in the cortex of young animals and that synthesis declines by $23 \mathrm{~d}$ of age (Fig. 3). GAP-43 was identified in the cortex sample by its comigration with axonally transported GAP-43 from pyramidal tract samples and by its aberrant shift in apparent molecular weight from $45 \mathrm{~K}$ on $12 \%$ acrylamide-SDS gels to approximately $60 \mathrm{~K}$ on the $5-15 \%$ acrylamide-SDS gels shown in Figure 3.

We also considered the possibility that GAP-43 is transported more slowly in mature axons, and so had not reached the medullary pyramidal tract at the times sampled. When we took pyramidal tract samples 3,6 , and $12 \mathrm{hr}$ after injection of label into the cortex of mature animals, no increase in GAP-43 labeling was found with the longer survival times (data not shown).

\section{Correlation of GAP-43 synthesis with axon elongation}

In normal hamsters, synthesis of GAP-43 is maximal during the first week of life and begins to decline after $8 \mathrm{~d}$ of age (Fig. 4). By $8 \mathrm{~d}$, those pyramidal tract axons that are destined for the most rostral levels of the spinal cord have stopped elongating, while other axons continue to grow toward more caudal levels 

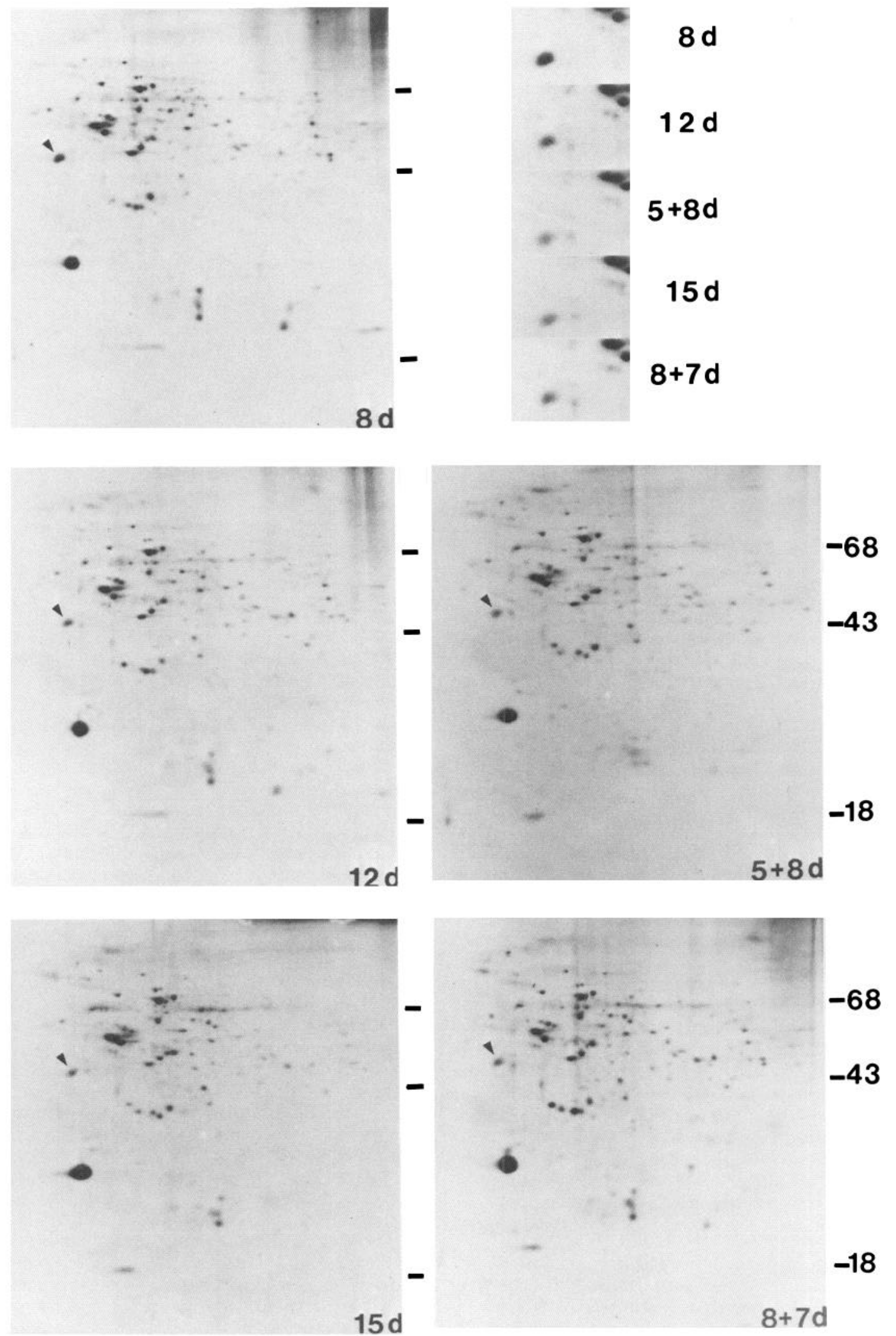

Figure 4. Early time course of decline in GAP-43 in normal and axotomized neurons. Newly synthesized proteins in pyramidal tract neurons were labeled in normal hamsters $8-15 \mathrm{~d}$ of age $(8 d, 12 d, 15 d)$. Also shown is one sample from an animal in which the cortex was labeled $8 \mathrm{~d}$ after a pyramidal tract lesion made on postnatal day $5(5 d+8)$ and a second sample from an animal in which the cortex was labeled $7 \mathrm{~d}$ after a lesion made on postnatal day $8(8 d+7)$. Pyramidal tract samples from these animals were taken from a region of the medulla above the lesion. Electrophoresis in the second dimension was carried out in the absence of urea. Fluorographs were exposed so that the product of the exposure time multiplied by the total amount of radioactivity applied to the gel was a constant for all samples. The fluorographs are oriented with the acidic end to the left, and the position of GAP-43 is indicated by arrows.Vignettes at upper right, Regions of the fluorographs containing labeled GAP-43. 


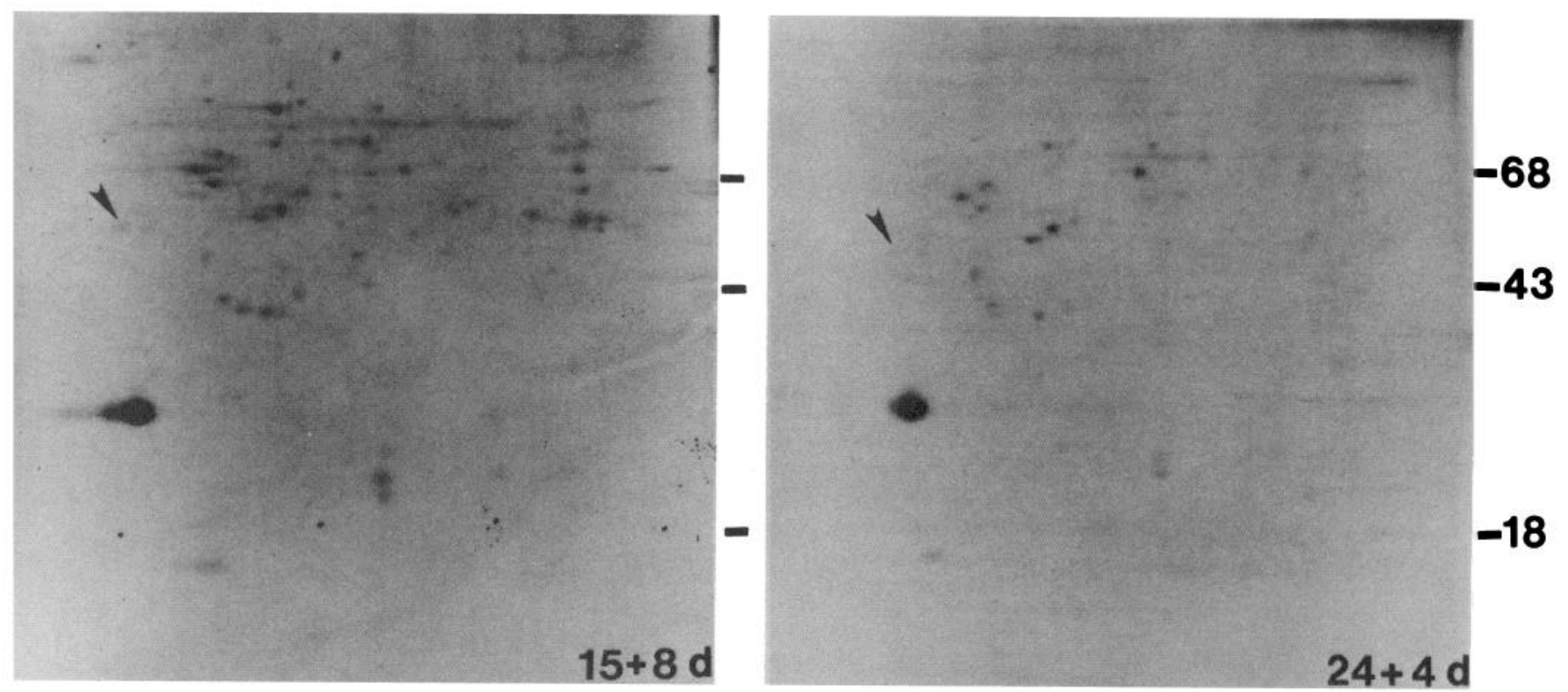

Figure 5. Failure of GAP-43 induction after axotomy in older animals. Pyramidal tracts were cut in animals 15 or $24 \mathrm{~d}$ of age as described in Figure 2, and ${ }^{35} \mathrm{~S}$-methionine was injected into the sensorimotor cortex 8 and $4 \mathrm{~d}$ later, respectively. Labeled proteins in the region of the pyramidal tract above the lesion were recovered and analyzed as described in Figure 4. The position of GAP-43 is indicated by arrows. Compare the labeling of GAP-43 in these samples with that shown during development (Fig. 4).

(Reh and Kalil, 1981). After day 8, therefore, the number of elongating axons sampled in the medullary pyramidal tract is decreasing. By day 14 , growing axons have reached the most caudal level of the spinal cord, and by $21 \mathrm{~d}$, lateral growth into spinal cord targets is essentially complete (Reh and Kalil, 1981). GAP-43 synthesis also approaches adult levels by the end of the third week of life. The decline in GAP-43 synthesis is thus well correlated with elongation of pyramidal tract axons.

\section{Neonatal axotomy does not affect GAP-43 synthesis}

We wanted to know whether, in response to injury, the normal developmental decline in GAP-43 synthesis is delayed or reversed. When the pyramidal tract was cut at either 5 or $8 \mathrm{~d}$ of age, and synthesis of GAP-43 measured 7-8 d later, GAP-43 synthesis showed the normal developmental decline (Fig. 4). Labeling of GAP-43 synthesis at a series of times from 4 to 15 $\mathrm{d}$ after the lesions confirmed that the decline in GAP- 43 synthesis followed the normal developmental time course. The hypothesis that elevated GAP-43 synthesis is important for axon elongation predicts that the injured axons should be able to grow for only a short period of time after injury, until GAP-43 synthesis declines too far to support further elongation. Consistent with this prediction, maximum regrowth of axons occurs if the lesion is made at 4-8 d of age, before GAP-43 synthesis begins to decline. Axons lesioned in 5- or 8-d-old hamsters regrow to the level of the rostral spinal cord by a week after the lesion and then do not grow further caudally (Kalil and Reh, 1979, 1982).

\section{Adult axotomy does not reinduce GAP-43 synthesis}

When pyramidal tracts are cut at increasing ages greater than 8 $\mathrm{d}$, both the number of regrowing axons and the distance over which the axons grow decline sharply. No regeneration is evident in animals more than 3 weeks old (Kalil and Reh, 1979, 1982). Failure of axon regeneration in older animals might be explained by failure to reinduce proteins expressed during developmental axon outgrowth. To test this possibility, we cut the pyramidal tract in hamsters 15-28 d of age and analyzed GAP43 synthesis 4,8 , and $15 \mathrm{~d}$ after the lesions. There was no evidence for reinduction of GAP-43 synthesis at any time after injury. Two of these samples are illustrated in Figure 5.

\section{Discussion}

We have shown that a protein similar to GAP- 43 from regenerating toad optic nerves is synthesized and transported into growing axons of the hamster pyramidal tract. Synthesis of this hamster protein declines as axons reach maturity and is not reinduced by axonal injury.

\section{Other growth-associated proteins}

Among "growth-associated proteins" induced during axon growth in many different systems, GAP-43-like proteins are the most consistently observed (Benowitz and Lewis, 1983; Heacock and Agranoff, 1982; Jacobson et al., 1986; Skene and Willard, 1981a, b; Theiler and McClure, 1978). In several, but not all, of these systems, 23-26K proteins (designated GAP-24 in toads) are also induced in association with axon growth (Benowitz et al., 1981; Bisby, 1982; Skene and Willard, 1981a, b). GAP-24 does not appear to be a prominent developmentally regulated protein in hamster pyramidal tract neurons. In some of our experiments, we have observed a labeled protein with an isoelectric point and apparent molecular weight similar to GAP24 from regenerating toad optic nerves (e.g., Fig. 1). The appearance of this protein, however, is not consistent from one experiment to another, nor have we been able to detect the reproducible appearance of a GAP-24-like protein using the specialized gel systems employed by Skene and Willard (1981a) to resolve this protein. In view of the rapid turnover of GAP24 in vivo (Skene and Willard, 1981c), we cannot exclude the possibility of selective proteolysis of GAP-24 during the preparation of hamster pyramidal tract samples, but addition of protease inhibitors to our homogenization buffers does not affect our results. We conclude tentatively that elevated expression of GAP-24 is less strictly correlated with axon elongation than elevated expression of GAP-43. It is possible that this protein participates in some aspect(s) of growth that are not common to all instances of axon elongation.

\section{Quantitation of changes in GAP-43}

Densitometric scanning shows that labeling of GAP-43, expressed relative to total incorporated radioactivity in the pyramidal tract, is approximately 10-12 times greater in 12-d-old 
hamsters than in 28-d-old animals. This number is a significant underestimate for the following reason. After injection of ${ }^{35} \mathrm{~S}$ methionine into sensorimotor cortex, samples of the medullary pyramidal tract contain 2 populations oflabeled proteins - those labeled in cortex and transported into the medulla through pyramidal tract axons and those synthesized by cells in the medulla incorporating free ${ }^{35} \mathrm{~S}$-methionine that had leaked from the injection site. In very young animals, leakage of label from the injection site and the relatively short distance between the injection site and medulla make the locally labeled population of proteins a large fraction of the total incorporated radioactivity in the medulla. Local incorporation of radioactive label accounts for a decreasing fraction of total radioactivity with increasing age, as the increasing size and consistency of the brain limit the amount of free label reaching the medulla. Thus, the labeling of GAP-43 in young animals is normalized to an artifactually larger number than in older animals. Since it is very difficult to account for this difference quantitatively, we have used the most conservative estimate for the developmental change in GAP43. The real elevation of GAP-43 synthesis during developmental elongation of hamster pyramidal tract axons probably falls within the range of changes in GAP-43 synthesis reported during axon growth in other systems (Benowitz and Lewis, 1983; Skene and Willard, 1981a, b).

\section{Mechanisms of regulation}

Regardless of any direct role GAP-43 may play in axon growth, the close correlation between elevated GAP-43 synthesis and axon elongation makes induction of this protein a useful marker for studying biochemical pathways regulating axon growth. Several mechanisms could be proposed for the developmental regulation of GAP-43. Benowitz et al. (1983) have provided evidence that the decline in synthesis of a GAP-43-like protein after regeneration of goldfish optic nerves does not depend on interaction between the regenerating axons and their normal synaptic targets. Our observation that lesions of the pyramidal tract neither prevent nor delay the decline of GAP-43 synthesis is also consistent with target-independent regulation of GAP43 in neonatal hamsters. Several possibilities remain. Our observations do not rule out the possibility that an intrinsic developmental clock in neurons controls the level of GAP-43 expression, but in view of the extensive evidence that some growth-related mechanisms in neurons are responsive to the local environment (e.g., Schwab and Thoenen, 1985; So and Aguayo, 1985), we are interested in whether GAP-43 is environmentally regulated. Our results are difficult to reconcile with any form of regulation in which the sole regulator of GAP-43 is a diffusible inducer in the environment that is turned off in response to axons as they grow along the pathway. If this were the case, the inducer should continue to be produced in the pyramidal tract distal to neonatal lesions, resulting in prolonged synthesis of GAP-43.

Two forms of environmental regulation of GAP-43 are consistent with our observations. The maturing CNS might cease production of a GAP-43 inducer in a way that does not depend on the presence of axons. Instead, or in addition to any inducers of GAP-43, the maturing CNS environment might produce an inhibitor of GAP-43 synthesis, either in response to maturing axons or independently. In the latter case, inhibitor produced along the pyramidal tract proximal to a lesion site could be responsible for the decline in GAP-43 synthesis following neonatal injury. Such an environmental inhibitor of GAP-43 synthesis, and growth-related events for which it can serve as a marker, could explain why some mammalian CNS axons regenerate into peripheral nerve grafts only if the grafts are placed close to the CNS cell bodies, leaving a minimum length of axon still in contact with the CNS environment (David and Aguayo, 1981; Richardson and Issa, 1984; So and Aguayo, 1985).

\section{Conclusion}

Our current observations strengthen the correlation between elevated GAP-43 synthesis and axon elongation. The normal time course of GAP-43 synthesis closely parallels normal developmental outgrowth of pyramidal tract axons, and the limited period of axon regrowth after neonatal pyramidal tract injury coincides with the limited period during which GAP-43 continues to be expressed at an elevated level. Our results therefore add support to the hypothesis that GAP-43 participates in some aspects of axon growth. Direct participation of GAP-43 in axon growth is also suggested by evidence that GAP-43 is a major component of growth cone membranes (Meiri et al., 1986; Skene et al., in press). The failure of pyramidal tract injury to reinduce GAP-43 synthesis in older animals is similar to the failure of GAP induction after injury to adult rabbit optic nerves (Skene and Willard, 1981b), suggesting that failure to reinduce GAP-43 synthesis after injury may be common to many mammalian CNS pathways and that GAP-43 synthesis may be one limiting event in the growth and regeneration of mammalian CNS axons.

\section{References}

Benowitz, L. I., and E. R. Lewis (1983) Increased transport of 44,000to 49,000 -dalton acidic proteins during regeneration of the goldfish optic nerve: A two-dimensional gel analysis. J. Neurosci. 3: 21532163.

Benowitz, L. I., V. E. Shashoua, and M. G. Yoon (1981) Specific changes in rapidly transported proteins during regeneration of the goldfish optic nerve. J. Neurosci. 1: 301-307.

Benowitz, L. I., M. G. Yoon, and E. R. Lewis (1983) Transported protcins in the regenerating optic nerve: Regulation by interactions with the optic tectum. Science 222: 185-187.

Bisby, M. A. (1982) Prolonged alteration in composition of fast transported protein in axons prevented from regenerating after injury. $J$. Neurobiol. 13: 377-381.

David, S., and A. J. Aguayo (1981) Axonal elongation into peripheral nervous system "bridges" after central nervous system injury in adult rats. Science 214: 931-933.

Heacock, A. M., and B. W. Agranoff (1982) Protein synthesis and transport in the regenerating goldfish visual system. J. Neurochem. Res. 7: 771-788.

Jacobson, R. D., I. Virág, and J. H. P. Skene (1986) A protein associated with axon growth, GAP-43, is widely distributed and developmentally regulated in rat CNS. J. Neurosci. 6: 1843-1855.

Jen, G., and R. E. Thach (1982) Inhibition of host translation in encephalomyocarditis virus-infected cells: A novel mechanism. J. Virol. 43: $250-261$.

Kalil, K., and T. Reh (1979) Regrowth of severed axons in the neonatal central nervous system: Establishment of normal connections. Science 205: 1158-1161.

Kalil, K, and T. Reh (1982) A light and electron microscopic study of regrowing pyramidal tract fibers. J. Comp. Neurol. 211: 265-275.

Laemmli, U. K. (1970) Cleavage of structural proteins during the assembly of the head of bacteriophage T4. Nature 227:680-685.

Laskey, R. A., and A. D. Mills (1975) Quantitative film detection of ${ }^{3} \mathrm{H}$ and ${ }^{14} \mathrm{C}$ in polyacrylamide gels by fluorography. Eur. J. Biochem. 16: $1-14$.

Meiri, K. F., K. H. Pfenninger, and M. B. Willard (1986) Growthassociated protein, GAP-43, a polypeptide that is induced when neurons extend axons, is a component of growth cones and corresponds to pp46, a major polypeptide of a subcellular fraction enriched in growth cones. Proc. Nat. Acad. Sci. USA 83: 3537-3541.

O'Farrell, P. H. (1975) High-resolution two-dimensional electrophoresis of proteins. J. Biol. Chem. 250: 4007-4021.

Reh, T., and K. Kalil (1981) Development of the pyramidal tract in the hamster. I. A light microscopic study. J. Comp. Neurol. 200: 5567

Reh, T., and K. Kalil (1982) Functional role of regrowing pyramidal tract fibers. J. Comp. Neurol. 211: 276-283.

Richardson, P. M., and V. M. K. Issa (1984) Peripheral nerve injury enhances central regeneration of primary sensory neurones. Nature 309: 791-793. 
Schwab, M.E., and H. Thoenen (1985) Dissociated neurons regenerate into sciatic but not optic nerve explants in culture irrespective of neurotrophic factors. J. Neurosci. 5: 2415-2423.

Skene, J. H. P., and M. Willard (1981a) Changes in axonally transported proteins during axon regeneration in toad retinal ganglion cells. J. Cell Biol. 89: 86-95.

Skene, J. H. P., and M. Willard (1981b) Axonally transported proteins associated with axon growth in rabbit central and peripheral nervous systems. J. Cell Biol. 89: 96-103.

Skene, J. H. P., and M. Willard (1981c) Characteristics of growthassociated polypeptides in regenerating toad retinal ganglion cell axons. J. Neurosci. 1: 419-426.
Skene, J. H. P., R. D. Jacobson, G. J. Snipes, C. B. McGuire, J. J. Norden, and J. A. Freeman (in press) A protein induced during nerve regeneration (GAP-43) is a major component of growth cone membranes. Science.

So, K.-F., and A. J. Aguayo (1985) Lengthy regrowth of cut axons from ganglion cells after peripheral nerve transplantation into the retina of adult rats. Brain Res. 328: 349-354.

Theiler, R. F., and W. O. McClure (1978) Rapid axoplasmic transport of proteins in regenerating sensory nerve fibers. J. Neurochem. 31: $433-447$. 